\title{
Research on E-commerce Curriculum Reform in the Age of Mobile Internet
}

\author{
Zhou Jian, Zhao Zhenyi* \\ Wenzhou Vocational College of Science and Technology, Wenzhou, Zhejiang, 32500
}

Keywords: e-commerce; mobile Internet; curriculum reform

\begin{abstract}
In the new era, the focus of e-commerce majors on talent training has changed, and the corresponding curriculum and curriculum content selection should also be adjusted. The urgency of e-commerce curriculum reform is more obvious, and the corresponding curriculum reform issues must be better coordinated with new characteristics and development trends. This paper will study the series of curriculum reform issues, and put forward reasonable suggestions on how to improve the curriculum reform.
\end{abstract}

\section{Introduction}

Although the new curriculum reform is deepening, the process of e-commerce curriculum reform is relatively slow. Because the college e-commerce major has certain speciality in talent training, it needs to pay attention to the balanced development of students' theoretical knowledge and hands-on ability. The corresponding reforms carried out at the end will also be affected by many factors. It can be seen that the e-commerce professional teaching and curriculum reform is imperative. However, the curriculum reform activities are difficult to carry out, and it is necessary to find a general path to better curriculum reform [1].

\section{Overview of e-commerce curriculum reform in the era of mobile internet}

The era of mobile Internet is a new stage in the development of the Internet era. Intelligent mobile portable devices such as mobile phones have been widely used in applications, and the Internet era with mobile devices as carriers has also come quietly. The era of mobile Internet has the characteristics of the basic era of fast information dissemination and large data volume. In this era, everyone is also the information and data disseminator in the actual sense. The popularity of mobile devices and the use of Internet technologies have had a significant impact on economic development, medical, transportation and education-related activities. Along with the increasing use of Internet technology and the maturity of Internet thinking, the connotation of the new era has become more and more abundant [2].

In the new era, the development of e-commerce professional teaching activities has been significantly affected. This influence has both the indirect impact of the education reform end and the direct impact of the change in talent demand. The reform of e-commerce professional teaching reform is inseparable from the corresponding curriculum reform attempts. The significance of successful curriculum reform is self-evident. First of all, education should be synchronized with the development of the times. Internet 2.0 has evolved into Internet 3.0. The impact of the Internet on human society is deeper. Under this circumstance, the reform of e-commerce professional curriculum can keep e-commerce professional education and the development of the times. Higher consistency and more targeted training. Secondly, curriculum reform in line with the development of the times can solve the problems that have always existed in the education of e-commerce professional education. Thanks to the continuous deepening of curriculum reform activities, colleges and e-commerce teachers can also stand at a higher angle. Examine the development of professional education and teaching activities. 


\section{The difficulty of e-commerce curriculum reform in the era of mobile Internet}

Although the urgency of the reform of e-commerce professional courses in colleges and universities is more obvious, in the actual operation of curriculum reform, the direction of reform is not clear. This is the most difficult point in the promotion of relevant activities of curriculum reform at this stage. I have to admit that the curriculum reform in any discipline at the higher education stage is a relatively systematic "engineering". Generally speaking, after clearing the direction of curriculum reform, the specific reform activities can proceed smoothly. Only the reform related trials can achieve good results. However, it is also necessary to see that different eras have different characteristics of the times. In this era, the needs of e-commerce professionals in the whole society, as well as in industries and enterprises, are also differentiated. Due to the influence of these factors, the direction of e-commerce professional curriculum reform is very difficult. Many colleges and e-commerce professional teachers do not know the direction of the curriculum reform attempt, which will lead to the overall The course reform process has become more and more slow, and the reform of e-commerce professional courses in colleges and universities has been slow to make breakthroughs [3].

In the development of e-commerce professional teaching activities, traditional educational concepts and teaching methods are still widely used, which has become a difficult point in the current e-commerce professional curriculum reform. From the perspective of curriculum reform, the purpose of curriculum reform is to transform educational concepts and teaching methods. The scientific transformation of educational concepts and teaching methods can also provide positive help for curriculum reform. Although the development of e-commerce professional teaching activities will not be affected by the concept of exam-oriented education, the practical teaching of the basic theoretical knowledge of the subject is too important, and the education concept is not updated from the perspective of the development of the times. The choice has become very mechanical. The teacher group has a certain dependence on the traditional educational concept and the traditional education and teaching methods have been widely used, and the internal environment of good curriculum reform and reform is difficult to form. From the perspective of improving the quality of e-commerce teaching or deepening the curriculum reform, traditional educational concepts and educational methods need to be adjusted accordingly. It is still impossible to provide e-commerce teaching mechanically. help.

At present, the setting of e-commerce professional courses and the content setting in the existing courses are unreasonable, especially the irrationality of professional curriculum has become a hindrance factor for the e-commerce professional curriculum reform. Through the analysis of the existing courses of e-commerce, it can be found that the theoretical knowledge courses account for a large proportion, and there is a certain difference between the content of professional courses and the development of e-commerce industry in the new era. Many e-commerce professional teachers do not completely follow the textbooks when they explain their professional knowledge, but their courseware design is not based on the basic defense of curriculum reform. Once the professional curriculum is unreasonable, it is impossible to provide some practical teaching experience for the curriculum reform on the actual teaching side, and the deepening of the curriculum reform will become more and more difficult. Once the unreasonable problems in the e-commerce professional curriculum are not solved, other curriculum reform attempts are also difficult to achieve success, which will further slow down the efficiency of curriculum reform and increase the pressure of curriculum reform. The setting of professional courses has become the paradox of the curriculum reform. When the problems in the professional curriculum are not solved, the curriculum reform will naturally be in a state of stagnation.

The reform and promotion of students in the e-commerce professional curriculum reform is often neglected. Many colleges and universities have set their sights on schools and teachers in the course of curriculum reform, and naturally exclude students from professional curriculum reform. Not only that, in the whole process of e-commerce professional curriculum reform, the student group has relatively few opportunities for practical training and practical exercises. The lack of opportunities 
for students to practice and practice first leads to a single level of e-commerce teaching. It is also difficult for teachers to have a better perception of students' knowledge and ability to use. The e-commerce professional curriculum reform itself should serve the students' teaching and talent cultivation, but the ability to master and apply the knowledge of the student group will increase the blindness of e-commerce professional curriculum reform. When the student group is unable to apply the knowledge learned, the curriculum reform of the e-commerce major will have more limitations, that is, the reformed curriculum can not help the e-commerce profession to better carry out knowledge teaching or new e-commerce professionals. Cultivation. Therefore, the fact that the specific teaching activities are carried out without good practical training for students has become a difficult point in curriculum reform. The inability of students to apply the knowledge they have learned has also led to a weaker link between curriculum reform activities and teaching [4].

\section{Countermeasures for the reform of e-commerce curriculum in the era of mobile internet}

The curriculum reform activities should be carried out in combination with the basic characteristics of the times. The era of the use of Internet technology is an era of continuous development and change. The e-commerce model is not only emerging, but also some new e-commerce theories. The e-commerce professional curriculum reform activities need to be better perceived by these changes, and it is more feasible to carry out e-commerce professional curriculum reform experiments in combination with the characteristics of the mobile Internet era. It is suggested that colleges and universities should first analyze the connotation of the era of the new era and the impact of the new era on the education and teaching activities of e-commerce in the planning of e-commerce professional curriculum reform. On this basis, professional teachers need to deepen their understanding of the characteristics of specific times, and better perceive some new changes in the current e-commerce professional education and e-commerce professional curriculum reform. By linking the professional curriculum reform with the development of the times, and taking the basic characteristics of the new era as an opportunity to carry out the reform of the e-commerce professional curriculum, the difficulty of professional curriculum reform will be significantly reduced, and the direction of reform can be more clear. Once this kind of curriculum reform idea can be established and applied in the development of specific education and teaching activities, the progress of college e-commerce professional curriculum reform activities can also be more coordinated at the same time [5].

The curriculum reform is inseparable from the continuous optimization of e-commerce professional education concepts and methods. Under the influence of traditional educational concepts, more mechanical teaching methods are widely used, which has had a negative impact on the e-commerce professional curriculum reform. In view of this, it is necessary to start from the optimization of educational concepts and the optimization of teaching methods in order to better carry out the curriculum reform attempt at this stage. It is recommended that e-commerce professional teachers carry out the education and training of compound talents under the principle of people-oriented education, and obtain some key teaching feedback through interaction and communication with the student groups in the classroom teaching. E-commerce professional teachers should explain the differences in the theory and practice of e-commerce professional knowledge to students, so that professional teaching can better conform to the actual development of the industry. After the education concept and the education method are continuously optimized, the internal environment of curriculum reform can be reshaped, the flexibility of e-commerce professional education activities and the adjustable space for curriculum reform will continue to increase, which can spur curriculum reform. move forward.

The curriculum reform and continuous deepening should be based on long-term adjustments in the professional curriculum. Especially at this stage, the irrational professional curriculum is set to restrict the professional curriculum reform. The professional curriculum is also better for the e-commerce professional curriculum reform. Prerequisites. It is recommended that colleges and universities in the professional curriculum set to fine-tune and reduce the actual proportion of pure theoretical courses. For example, information processing technology and mobile payment 
technology are two very important core technologies. Colleges and universities may consider adding information processing technology and mobile payment technology related courses in the e-commerce professional curriculum. The goal of curriculum reform is to better promote the development of e-commerce professional teaching activities, and to carry out more e-commerce professional talent training. Therefore, the curriculum should also pay attention to the objectives of curriculum reform. Thanks to the more reasonable curriculum, curriculum reform can be better linked to the development of general teaching activities, which is very helpful to reduce the actual resistance of e-commerce professional curriculum reform. Not only that, after the professional curriculum has been optimized, teachers can have a new understanding and perception of the curriculum reform issues in the development of teaching activities, which can also provide a lot of help for the curriculum reform.

The curriculum reform in the development of e-commerce professional teaching activities requires the joint efforts of teachers and students, and teachers or schools unilaterally carry out curriculum reform efforts can not succeed. The student group is the demand side of the education service, and some opinions of the student group on the e-commerce professional teaching activities can also become an effective reference for the curriculum reform. Various professional practice teaching activities need to become the basic components of e-commerce professional education and teaching activities. After conducting some narrative knowledge, teachers can create some practical training activities and participate in these practical activities through students. Test students' knowledge and ability to use knowledge. The use of continuous training and improvement of students' hands-on ability, continuous evaluation of students' knowledge understanding and application status, e-commerce professional teachers need to carry out the fine-tuning of the direction of professional curriculum reform. Creating more hands-on opportunities for students and enabling students to apply what they have learned into practice is a new direction in the development of e-professional education. The student group has a better ability for their professional ability, especially their ability to work. After good perception, it can not only participate in the reform of e-commerce professional curriculum, but also contribute to the reform of e-commerce professional curriculum. The deepening of curriculum reform cannot be taken for granted. Especially when there is no set of curriculum reform model that can be used at this stage, it is very feasible for teachers and students to participate in the curriculum reform. This is to reduce the turnover rate of curriculum reform and improve curriculum reform. The accuracy is very helpful.

\section{Conclusion}

The e-commerce curriculum reform must not only keep pace with the development of the times, but also focus on the needs of talent cultivation. Even if there are many realistic factors affecting and restricting curriculum reform, under the background of more obvious urgency of reform, colleges and e-commerce teachers should think more about how to carry out curriculum reform. It is worth noting that although the progress and deepening of curriculum reform can be carried out from many angles and levels, no matter what kind of curriculum reform attempts, it is necessary to adhere to the basic principle of student-oriented and avoid inappropriate curriculum reform to try routine teaching. have negative impacts.

\section{References}

[1] Qin W S. Discussion on the Teaching Reform of Communication Course in Higher Vocational on Internet Plus Era[J]. Journal of Liuzhou Vocational \& Technical College, 2017.

[2] Dai Y J, Wei H E, Yuan S, et al. The reform and practice of the Microbiology Experiment course under the "Internet +" era[J]. Microbiology China, 2018.

[3] Yin Hongbiao, Lee John, Chi-Kin Wang, Wenlan. Dilemmas of Leading National Curriculum Reform in a Global Era: A Chinese Perspective. [J]. Educational Management Administration \& 
Leadership, 2013, 42(2):293-311.

[4] Jun W U, Yang J P. Management Information System Curriculum Reform for the Inter-disciplinary Talents in Internet Era[J]. Journal of Beijing University of Posts \& Telecommunications, 2016.

[5] Jiao J L, Xiong Z G, Zhang X M, et al. Research on the Role of "Mobile Programming" Course in Teaching Curriculum Reform of Computer Science and Technology[C]// International Conference on Education Technology \& Training. 2010:65-69. 